\title{
ION PLATED THIN METALLIC FILM LUBRICANTS FOR ROCKETS AND SPACE VEHICLES
}

\author{
F. SALEM ${ }^{*}$ and M. EL-SHERBINY **
}

\section{ABSTRACT}

This paper presents experimental results on the frictional behaviour of ion plated soft metallic films.

The conventional ion plating process is used to deposit low melting point materials such as silver, lead, indium, and tin. Tribotesting of the coatings is made both in ultrahigh vacuum and in normal atmosphere on a pin-disc machine.

The results indicate that an intermetallic composition of $60 \%$ $\mathrm{pb}, 25 \% \mathrm{In}, 10 \% \mathrm{Sn}$ and $5 \% \mathrm{Ag}$ is the best for its low friction and long life.

\section{INTRODUCTION}

The tendency in recent years to subject sliding surfaces to an ever increasing range of thermal, mechanical and environmental stresses has inevitably posed new problems in friction and wear. Conventional mineral oils are unable to lubricate effectively at temperatures in excess of $150^{\circ} \mathrm{C}[1]$. On the other hand there are many applications which require solid lubricants which can withstand particular operating conditions and environmental. Falling into this category are the bearings and seals of rockets and space vehicles [2-4]. In such cases the lubricants are supposed to operate for short periods of time in radiation environment, in liquid hydrogen or in ultrahigh vacuum $[5,6]$. A material selected for radiation application should not become excessively radioactive. Therefore soft metals are the most logical condidates [7].

The duration of an operating cycle for a rocket vehicle's bearing is relatively short, and the total operating life is measured in minutes. In such cases an effective solid lubricant of relatively short life is acceptable, providing that it

* Associate Professor, Cairo University, Cairo, Egypt

**Associate Professor, on leave from Cairo University (Present address: Dept. of Mech. Engg., King Abdulaziz L University, Saudi Arabia). 
has the necessary radiation resistance.

The common metallic components of plain bearing shells (e.g. lead, tin, silver and indium) have good lubrication properties; in particular a low shear strength and transfer-film forming tendency. They also enjoy a good radiation resistance, which makes them the most acceptable lubricants for such applications.

The ultimate solution, therefore, assumes a structural material of high strength to weight ratio for the bearing covered with a soft metallic film for the lubrication purposes.

When a coating is applied to a surface, the application method determines the bonding characteristics and adherence. These are reflected on the effectiveness and usefulness of the coating during its functional life. Ion plating [8-10] is a physical vapour deposition process for which outstanding adhesion was frequently claimed.

It is therefore the objective of this paper to examine the effectiveness of various soft metallic coatings for space lubrication.

\section{EXPERIMENTAL}

Film Deposition.

A conventional ion plating unit IPAC-30 was used for depositing soft metallic films of $\mathrm{Pb}, \mathrm{In}, \mathrm{Sn}$, and Ag as well as intermetallic compounds of these elements. Fig.l shows a schematic drawing for the deposition set up. The usual deposition procedure is to pump the chamber down to a vacuum of $10^{-6}$ torr, before admiting an inert gas (Argon) to a pressure of 10-25 $\mu \mathrm{m} \mathrm{Hg}$. A high tension power supply of up to $6 \mathrm{Kv}$ is connected to the substrate (cathode) to provide the supporting gas plasma. The Argon plasma is maintained for 20 minutes to sputter clean the substrate. As the heating filaments (Molybdenum boats) are switched on the metal vapour of the film material is enjected into the plasma, partially ionized and accelerated towards the substrate. Consequently a thin adherent film of the depositing neutrals is thereby formed.

The use of multi-heating element permits the simultaneous evaporation and deposition of intermetallic compounds with good control on the deposit composition.

\section{Tribotesting.}

A conventional pin-disc machine was used for testing the films in normal atmosphere. A $6 \mathrm{~mm}$ diameter spheres of EN-31 steels were coated and used as spherical ends for the pin of the machine. The mating surface however is EN-31 steel disc of $10 \mathrm{~cm}$ outside diameter, hardened to the same hardness of the balls ( $900 \mathrm{VHN})$. The load is applied by dead weights within L the range $0.5-4.0 \mathrm{~kg}$, while the motor speed is maintained at 


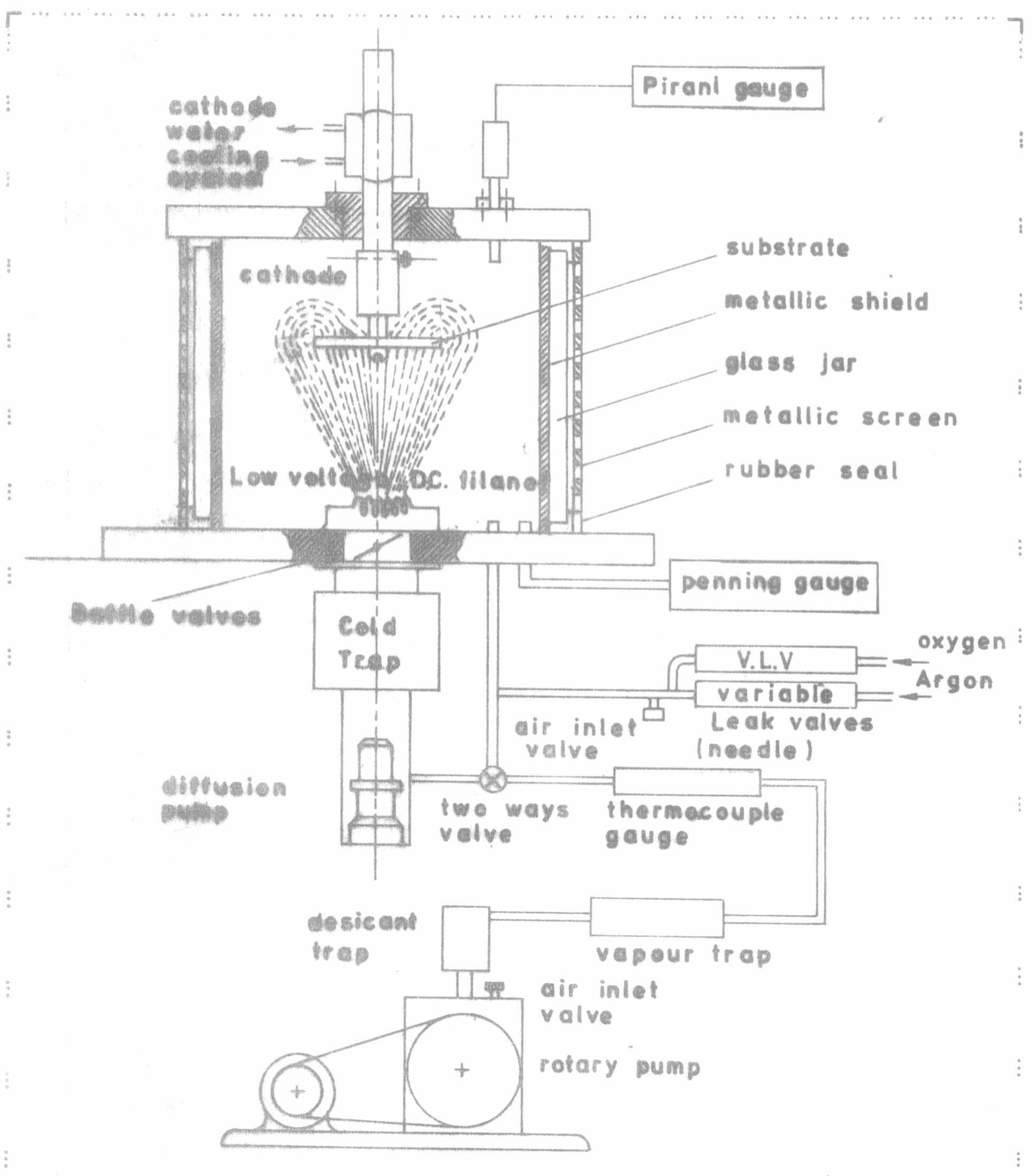

Fig.1 Schematic layout of the ion plating set up

a preselected value within the range 10-10000 rpm.

Tests made in high vacuum, however, utilized a smaller rider of $3.2 \mathrm{~mm}$ diameter, made of steel EN-31 balls. The specimen chamber containing the disc and the rider was continuously pumped down to $10^{-7}$ torr. In these tests the speed was kept constant at 10 r.p.m. 


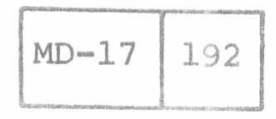

FIRST A.M.E. CONFERENCE

29-31 May 1984, Cairo

Specimen Preparation:

The friction discs were finely ground to $0.13 \mu \mathrm{m}$ along the machining marks and 0.18 across the machining marks. Test spheres of $0.1 \mu \mathrm{m}$ average surface roughness were ion plated with soft metallic films having thicknesses within the range $0.1-8 \mu \mathrm{m}$. The film materials were commercially pure (99.5\%) metals. The coated test spheres were ultrasonically cleaned and dried in air before testing.

\section{RESULTS AND DISCUSSION}

\section{Single Metal Films}

Figure 2 shows the transition from low to high friction of ion plated lead, indium, tin and silver, in normal atmosphere. At the start of the run the order of the friction coefficient is related to the shear strength of the four metals. During the run the appearance of the film changed for each material. The indium changed from shiny metallic to a greyish colour, whilst the lead changed to lustrous black. Both tin and silver films were tarnished by friction testing. X-ray analysis showed that the lead film suffered some oxidation by frictional heating in normal atmosphere and therefore it ultimately consisted of some combination of lead and lead oxide $\mathrm{PbO}$. The longer life of the lead film was therefore related to the lubrication properties of this oxide [11].

In high vacuum however no oxide film was detected in either case. The film colour however was tarnished by beded in wear debries from the steel substrates. Fig.3 shows the film life in high vacuum. It clearly demonstrate a longer life for each film as compared with the normal atmosphere results. This was attributed to transfer-back-transfere wear mechanism.

Effect of Normal Load:

Bowden and Tabor among others [12-15] reported that the friction of thin soft metallic films is load dependent. An elastic analysis of the Hertzian contact of thin films showed that the relation between the load and the area of contact is markedly non-linear [16]. This suggests that Amonton's law will not be obeyed and this is strikingly demonstrated in both test results shown in figs. 4 and 5 for normal atmosphere and high vacuum environments respectively.

The effect of load on film life for each of the four metallic films is shown in figs. 6 and 7. In each case of the normal atmosphere tests (fig.6), the film life is essentially inversely proportional to the load, although more scatter of the results is obtained at the higher loads. X-ray diffraction. studies of the wear debries showed that at higher loads a greater amount of substrate material was present. At such loads it may be speculated that hard substrate particles resulted in abrasive wear in addition to the microcutting wear. [7]. In high vacuum however the scatter tends to be at low Lloads. This can be attributed to the transfex-back-transfer 


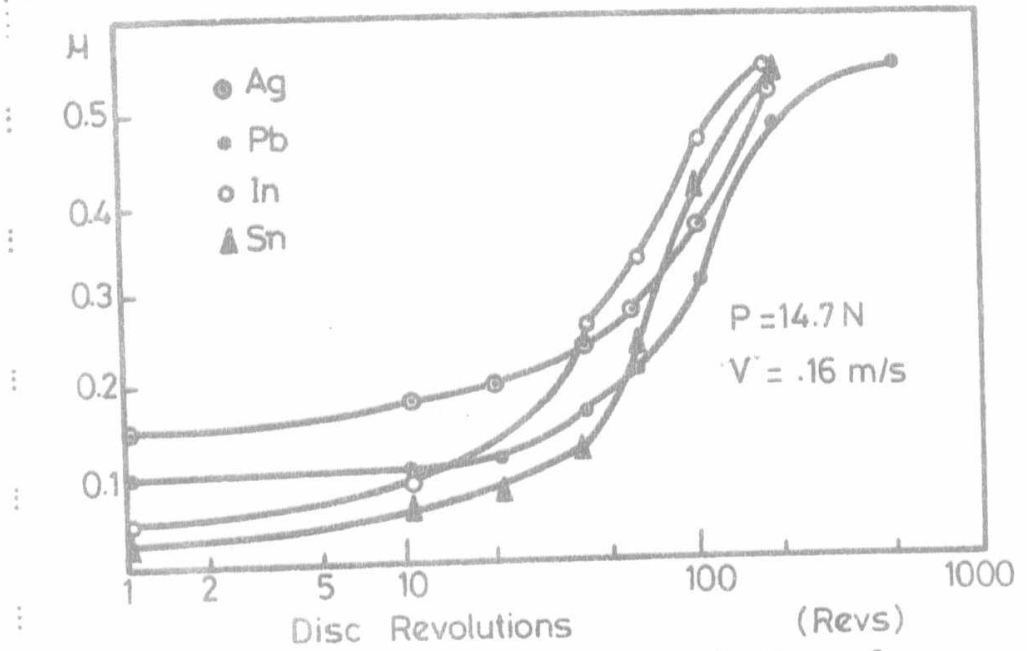

Fig:2 Friction Transitions in Normal Atmosphere.

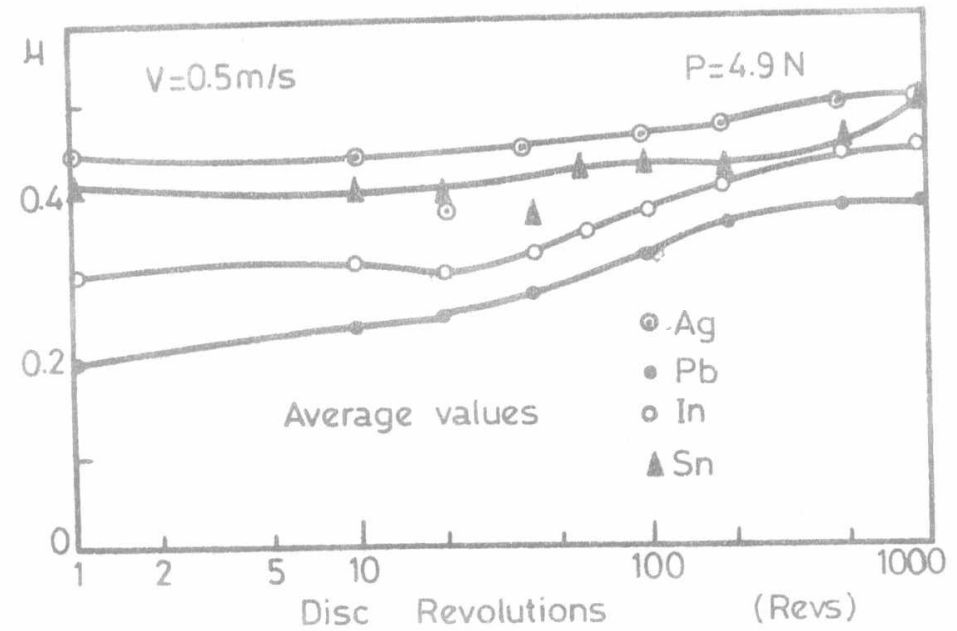

Fig:3 Friction History in Vacuum

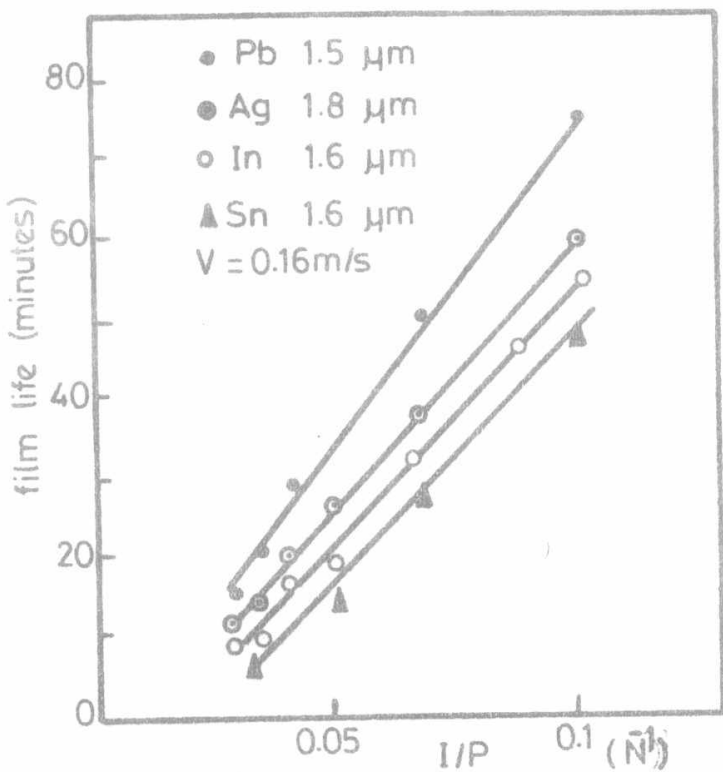

Fig:6 Load Effect On Life in Air

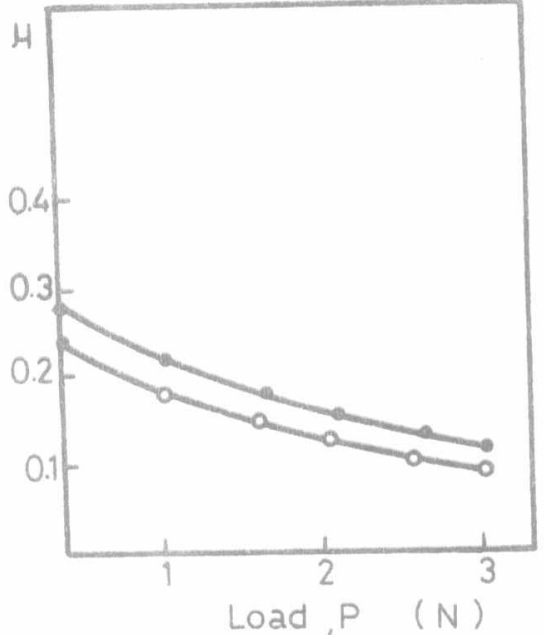

Fig: 4 Load Effects on $\mu$ in Air.

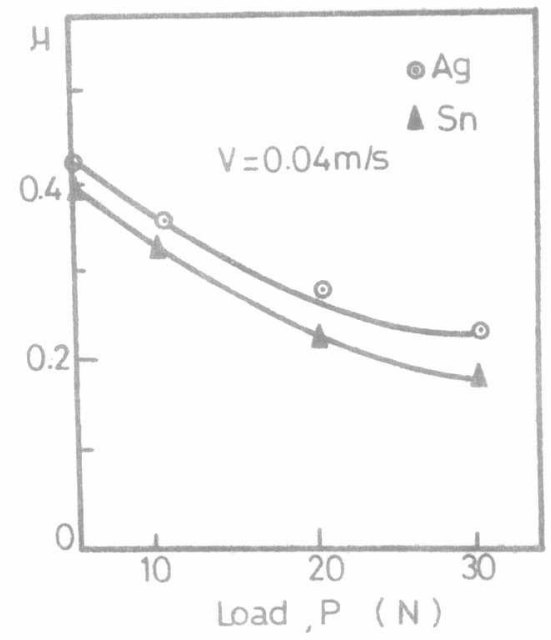

Fig:5 Load Effect on $\mu$ in Vacuum

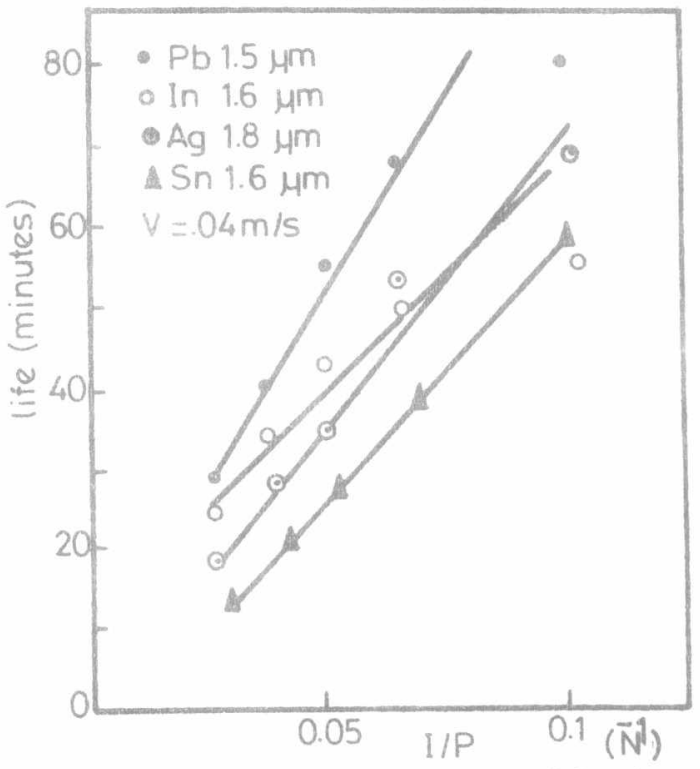

Fig:7 Ioad Effect On Life in Vacuum 
mechanism which is expected to work effectively at low loads increasing the film life.

Effect of sliding Velocity:

The coefficient of friction was measured after the tenth revolution of the disc for a range of sliding velocities. The results presented in Fig. 8 shows a maximum reduction of $20 \%$ in the coefficient of friction corresponds to an, increase in sliding speed of more than an order of magnitude. In high vacuum however the velocity was constant and therefore no data is available in this particular respect. The reduction in friction can be reasoned by film softèning by frictional heating. This thermal softening results in lower shear stresses without significant reduction in load carrying capacity.

The film life was seen to be more dependent on velocity than the coefficient of friction (Fig.9). For a given a film thickness the life of the film is interpreted approximately as the length of sliding to produce a given wear volume of films of the same initial thickness. These results are shown in Fig.10. It demonstrates that the generally accepted law that the wear volume is a linear function of the sliding distance is not universally true at different velocities of the multilayer sliding contacts.

The effect of increasing sliding speed is to produce higher contact temperatures and consequently higher degree of thermal softening. This would explain the behaviour of indium and tin films. On this basis the behaviour of lead is very surprising. This apparent discrepancy, which was also noted in the film life results (fig.2) is thought to be due to the presence of higher concentration of $\mathrm{PbO}$, which is a very effective lubricant.

Effect of Film Thickness.

The values of the initial coefficient of friction at different film thicknesses are shown in Fig.ll. A theoretical model has been recently proposed [18] to explain such behaviour. An equally important model for the wear rates as a function of film thickness [19] has also been considered.

Intermetallic Compounds.

Increasing attention has recently been paid to the self-lubricating effect of alloying several soft metals [20] for micromechanical and space applications. The combinations that results from consistant variations in the percentage of the present four metals are enormous. The low friction, high radiation resistance and long life of the load films however suggest using a lead based alloy. The low friction of indium also encourage a good percentage of indium in such alloy. The next candidate however would be tin for its stable behaviour. With silver being relatively harder and corrosion reL.. sistant it may be wise to limit its fractional volume. Two 


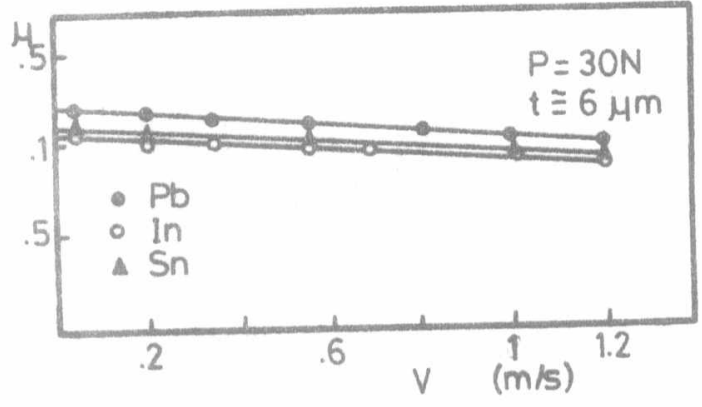

Fig: 8 Velocity Effect on $\mu$ (in Air)

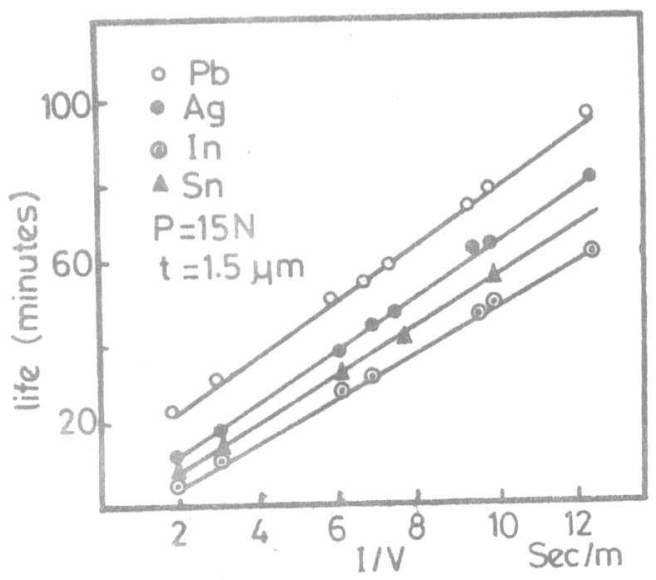

Fig:9 Velocity Effect on Life (in Air)

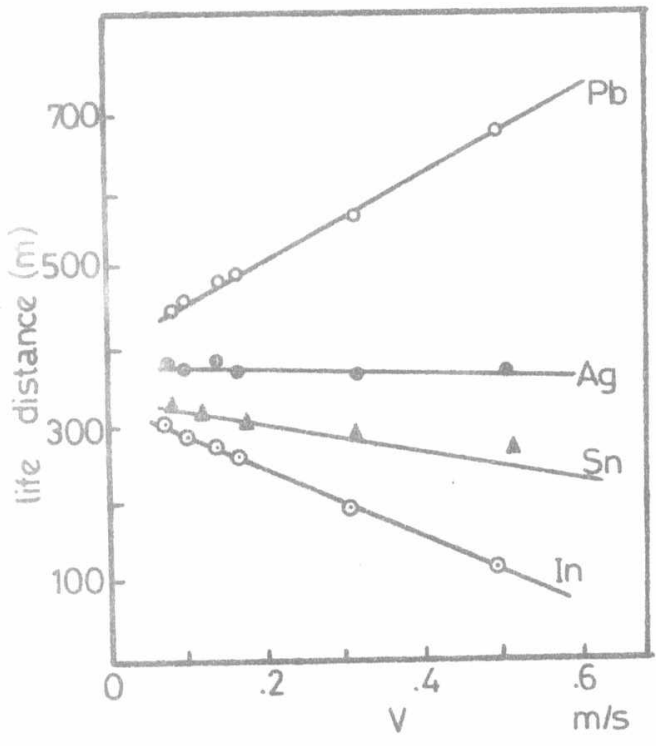

Fig:10 Velocity Effects on Life

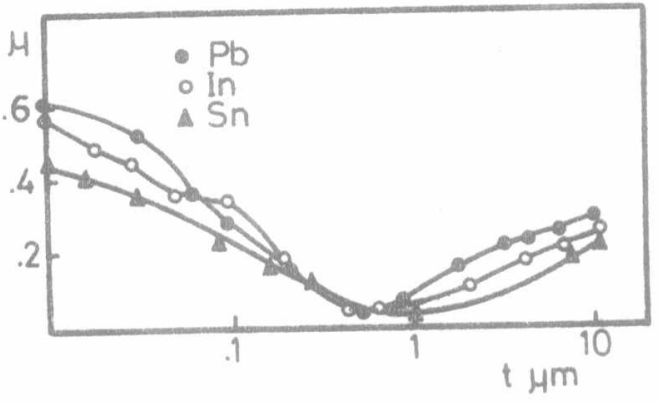

Fig:11 Film Thickness Effects on $\mu$

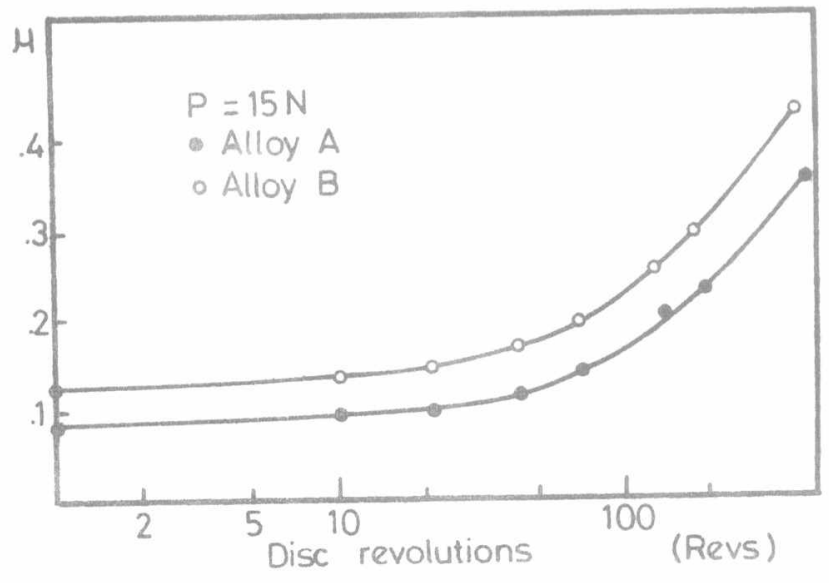

Fig:12 Friction History at High Loads

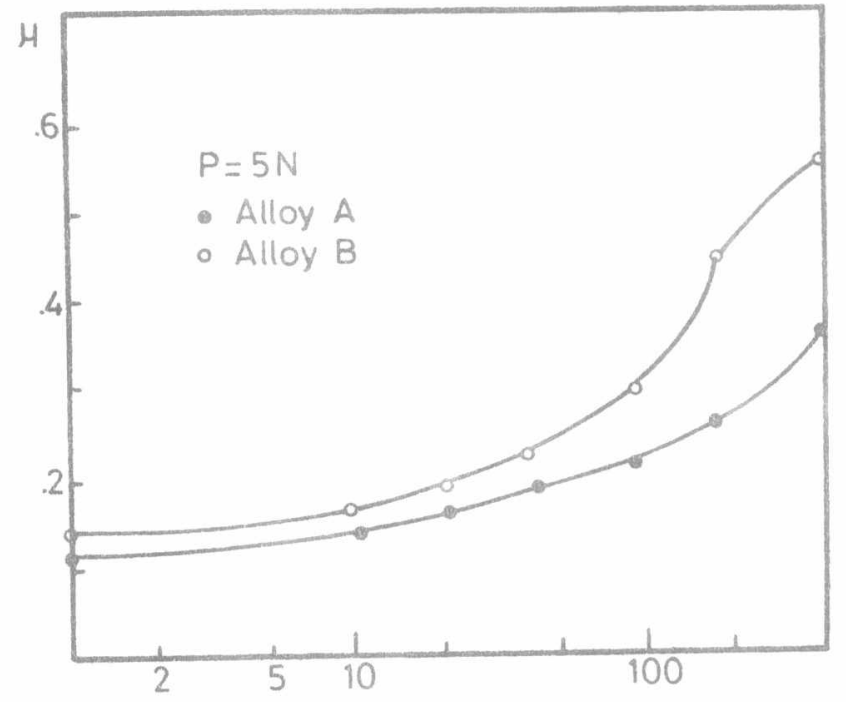

Fig:13 Friction History at Light Loads 
$\Gamma$

alloys were therefore made with the following compositions (a) 7 $60 \% \mathrm{~Pb}, 25 \% \mathrm{In}, 10 \% \mathrm{Sn}$ and $5 \% \mathrm{Ag}$ (b) $60 \% \mathrm{~Pb}, 25 \% \mathrm{Sn}, 10 \% \mathrm{In}$ and 5\% Ag. These were deposited by evaporation from two separate boats, the first containing lead and the second containing an alloy with the remaining required elements. The weight percentage was initially adjusted from the amount of metals to be evaporated. Figs. 12 and 13 show the coefficient of friction for the two alloys. These results indicate that the former alloy is superior to the second. Further work is still required to study some other possible combinations and to identify the developed phases. Fig.l4 shows a comparison between the developed wear scars in each case. It is interesting to note that the former alloy remained effectively over the entire area of the scar as compared with the latter which has been almost removed.

\section{CONCLUSION}

With ion plated lead films the production of lead oxide ( $\mathrm{PbO})$ which subsequently acts as a lubricant together with its high radiation resistance make this material particularly attractive for space applications. Indium and tin are also attractive for their initially low friction, and transfer-film forming tendency but these do not last long in oxidizing environments. Silver shows consistant behaviour irrespective of the operating conditions as a result of its relatively high hardness and oxidation resistance.

An alloy of $60 \%$ lead, 25\% indium, $10 \%$ Tin and 5\% silver showed. some promising characteristics of lubrication in space environment.

\section{REFERENCES}

[1] Cameron, A, "Principles of Lubrication," Longmans, London, p. 469, (1966).

[2] Freundilich, $M$, and Hannan, C, "Problems of Lubrication In Space," Lubrication Eng., 17, 72-77, (1961).

[3] Parker, E, "Materials For Missiles and Space Craft," McGraw Hill, New York, (1963).

[4] Brewe, D., Scibbe, H, and Wisander, D., "Performance of High Speed Ball Bearings With Lead and Lead-Alloy-Plated Retainers IN Liquid Hydrogen at 1.2 Million DN" "ASME Trans., J. Lub. Tech., July 74, 437-442, (1974).

[5] Brewe, D., Scibbe, H. and Anderson, W. "Film Transfer Studies of Seven Ball-Bearing Retainer Materials in $60^{\circ} \mathrm{R}$ $\left(33^{\circ} \mathrm{K}\right)$ Hydrogen Gas at 0.8 Million DN Value" NASA Tech. Note TND-3730,1, (1966).

[6] Wisander, D. "Lead, Indium, and Tin as Potential Lubricants in Liquid Hydrogen," NASA Tech. Note, TND-6455, I, (1971)。 

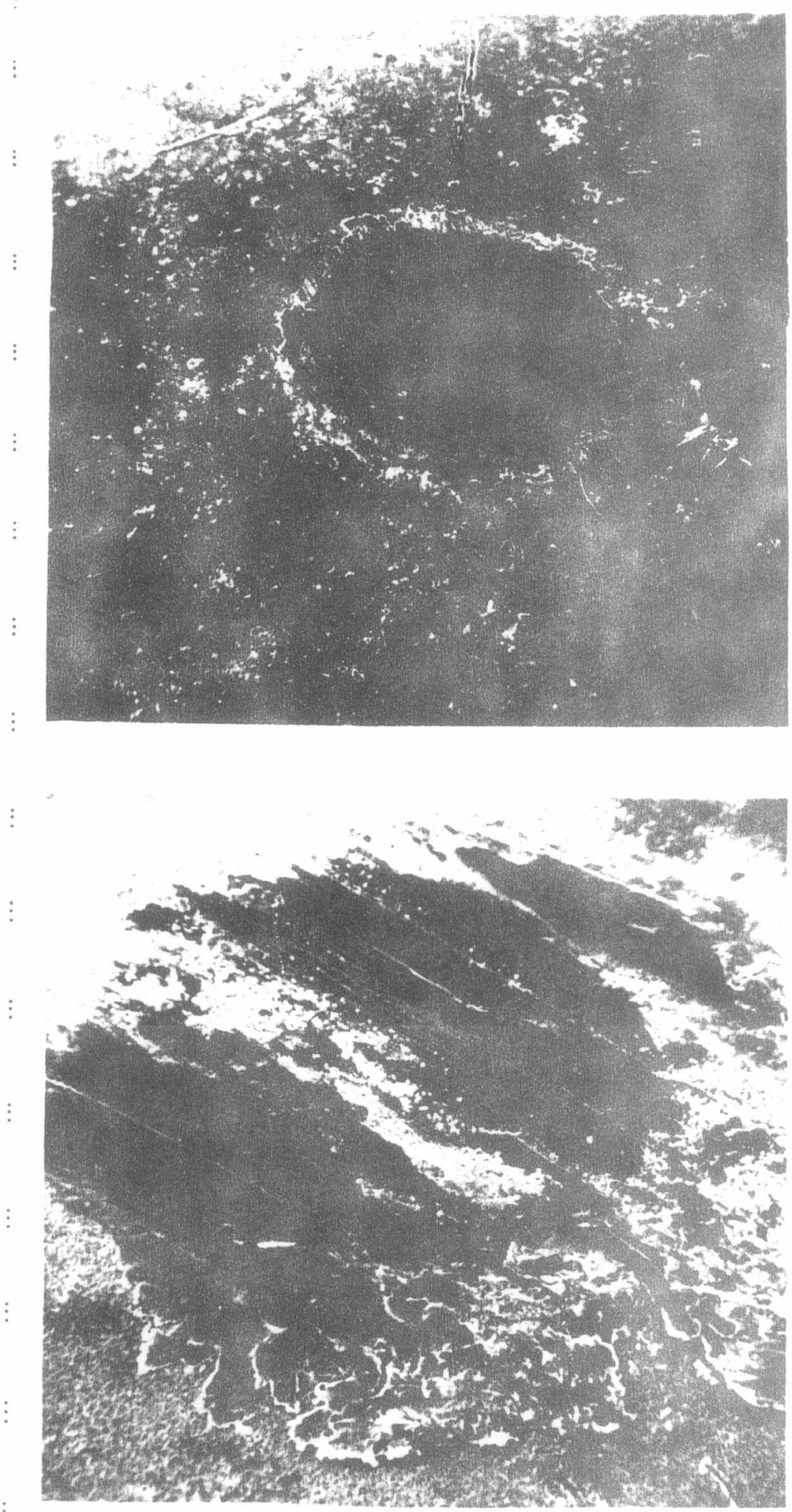

Wear scar of Alloy A.

Wear scar of Alloy $B$.

\footnotetext{
Fig.14 Comparison between the two wear scars of alloys $A$ and $B$.
} 
[7] El-Sherbiny, $M$. and Halling, J. "Friction and Wear of Ion-Plated Soft Metallic Films," Wear, 45, 211-220, (1977).

[8] El-Sherbiny, M. and Salem, F. "Fretting Resistant IonPlated Coatings," Amer. Soc. for Testing and Materials," in the book "Materials Evaluation Under Fretting Conditions,"ASTM-STP 780, 125-134, 1982 .

[9] Salem, F. and El-Sherbiny,M. "Wear Resistant Finishes," First Int. Conf. on Production, Design and Control, PEDAC, Alex. Univ. Paper MTSC-9, 1980.

[10] El-Sherbiny, M., Salem, F. and Aboukhashaba, A. "Ion Plated Transparent Conductive Films," J. Vacuum Technik, W. Germany, 32, 6, 168-173, 1983.

[11] Tsuya, Y. and Takagi, R. "Lubricating Properties of Lead" Films on Copper," Wear, 7, 131-143, (1964).

[12] Bowden, F. and Tabor, D. "The Friction and Lubrication of Solids," Oxford Univ. Press, Clarendon Press, Oxford, (1964).

[13] Bowden, F. and Tabor, D. "The Lubrication by Thin Metallic Films," J.Appl. Phys., 14, 141-151, (1943).

[14] Takagi, R. and Liu, T. "The Lubrication of Steel BY Electroplated Gold," ASLE TRANS., 10, 115-123, (1967).

[15] Burton, $R$. and Russel1, J. "Forces and Deformation of Lead Films in Frictional Processes," J. of the Amer.Soc. of Lub.Engrs., June 65, 227-233, (1965).

[16] El-Sherbiny, $M$. and Halling, J. "The Hertzian Contact of Surfaces Covered with Metallic Films," Wear, 40, 325-334, (1976).

[17] El-Sherbiny, M. and Salem, F. "Initial Wear Rates of Soft Metallic Films,"Wear, 54, p. 391-400, (1979).

[18] El-Sherbiny,M. "The Friction of Solid Lubricant Films: A Theoretical Approach," Accepted for Presentation in ASLE Conf. on "Solid Lubrication," To be held in Colorado U.S.A, August (1984).

[19] El-Sherbiny, M. and Salem, F. "A Wear Equation for Solid Lubricant Films," Accepted for presentation in ASLE Conf. on "Solid Lubricants" to be held in Colorado, U.S.A., August (1984).

[20] Aubert, F., Gass, H. and Hintermann, H. "Silver-Indium Self Lubricating Alloys," First European Tribology Congress, London 25-27, Sept. 73, paper C282/73, 201-206, (1973)。 